\title{
Spatial genetic structure of two sympatric neotropical palms with contrasting life histories
}

\author{
R Luna $^{1}$, BK Epperson ${ }^{2}$ and K Oyama ${ }^{1}$ \\ ${ }^{1}$ Centro de Investigaciones en Ecosistemas, Universidad Nacional Autónoma de México, Morelia, Michoacán 58190, México; \\ ${ }^{2}$ Department of Forestry, Michigan State University, East Lansing, MI 48824, USA
}

\begin{abstract}
The spatial genetic structure within sympatric populations of two neotropical dioecious palm species with contrasting life histories was characterized to evaluate the influence of life history traits on the extent of genetic isolation by distance. Chamaedorea tepejilote is a common wind-pollinated arboreal understory palm. Chamaedorea elatior is an uncommon climbing subcanopy palm with entomophilous pollination syndrome. A total of 59 allozyme alleles for $C$. tepejilote and 53 alleles for $C$. elatior was analyzed using both unweighted $\left(I_{\mathrm{u}}\right)$ and weighted $\left(I_{\mathrm{w}}\right)$ Moran's I spatial autocorrelation statistics. The spatial genetic structure detected within these populations is consistent with those reported for highly dispersed plants. A significance test for differences between mean Moran's I-coefficients revealed less spatial
\end{abstract}

Keywords: Chamaedorea; genetic structure; isolation by distance; Moran's l-statistics; neighborhood size; spatial autocorrelation

\section{Introduction}

Understanding the processes regulating similarities and differences of fine scale spatial genetic patterns between populations is a central focus in evolutionary biology. Genetic isolation for selectively neutral loci generally decreases rapidly as distance of separation increases (Malécot, 1948), and so does spatial autocorrelation of allele frequencies (Barbujani, 1987). Generally as gene dispersal increases, the spatial structure becomes increasingly diffuse, ultimately becoming virtually nonidentifiable (Epperson, 2003). However, the distribution of genetic variation within a plant population depends not only on pollen and seed dispersal, but also on mating patterns, survivorship through life cycle stages and the population density.

In outcrossing, polycarpic plants, reproduction is influenced by the individual reproductive periodicity, which determines the number of mating partners and effective pollination. Genetic isolation by distance within plant populations may be more strongly influenced by seed dispersal than by pollen flow (Hamilton, 1999). Hence, among sympatric and congeneric species, contrasts in either pollination or seed dispersal traits can affect spatial differences in genetic variation. In other words, the

Correspondence: K Oyama, Centro de Investigaciones en Ecosistemas, Universidad Nacional Autónoma de México. Antigua Carretera a Pátzcuaro 8701, Col. Ex-Hacienda de San José de la Huerta, C.P. 58190. Morelia, Michoacán, México. E-mail: akoyama@oikos.unam.mx Received 1 May 2004; accepted 31 January 2005; published online 6 April 2005 genetic structure within the $C$. tepejilote population than that in the $C$. elatior population. Adjacent individuals of $C$. elatior exhibited significant spatial genetic autocorrelation $\left(I_{\mathrm{u}}=0.039, I_{\mathrm{w}}=0.034\right)$, indicating a Wright's neighborhood size of about 100 individuals. For $C$. tepejilote, nonrandom genetic distribution among nearest neighbors was detected, even from small spatial autocorrelation values $\left(I_{u}=0.008\right.$, $I_{w}=0.009$ ), consistent with a neighborhood size of about 300 individuals. For both species, seed dispersal, mortality among life cycle stages, overlapping generations, and contrasting traits of mating and reproduction influence the standing spatial genetic structure within populations.

Heredity (2005) 95, 298-305. doi:10.1038/sj.hdy.6800655; published online 6 April 2005 relationship between alternative pollination mechanisms and spatial genetic structure among sympatric species also depends on contrasts in fruit attributes and seed dispersal modes. Small spatial-scale genetic structure should be lessened when the degree of spatial and temporal overlap of matrilineal family groups is greater (Hamrick et al, 1993; Vekemans and Hardy, 2004). Combining analyses of spatial genetic structure with observations of demography may allow greater insight into how the spatial distribution within populations is determined. In addition, standardized measures of dispersal such as Wright's (1943) neighborhood size may be accurately estimated from spatial autocorrelation (Epperson et al, 1999).

Studies of spatial genetic structure of non-woody plants from tropical rainforests are still scarce, particularly in climbing plants and palms, despite their substantial contribution to tropical rain forest diversity (Gentry, 1991; Henderson et al, 1995). Thus, an integrated understanding of microevolutionary processes that regulate and maintain spatial genetic structure of the most locally distinctive tropical species remains an outstanding topic in population evolutionary biology.

In this paper, we characterize the spatial genetic structure within populations of two Neotropical palms having contrasting life histories, Chamaedorea tepejilote and Chamaedorea elatior. Both species are long-lived perennial, polycarpic, dioecious and obligate outcrossers, showing annual reproduction and similar seed dispersal features. However, the species differ in pollination syndromes, growth forms, population density, spatial distribution, frequency of reproductive plants and individual reproductive periodicity. In this research, 
three objectives are addressed: (1) to study the influence of contrasting life histories on the spatial genetic structure within natural plant populations, (2) to estimate the extent of genetic isolation by distance within populations with high levels of genetic variability, and (3) to estimate the neighborhood size based on the total amount of gene dispersal. To achieve these objectives, weighted Moran's I-statistics and a significance test for differences between spatial autocorrelation coefficients are conducted

\section{Materials and methods}

\section{Study system}

Chamaedorea, the largest genus of Neotropical palms, includes approximately 77 species (Henderson et al, 1995). These dioecious palms are distributed in tropical rain forests from Mexico to Brazil and Bolivia (Hodel, 1992). Two Chamaedorea species showing contrasting life history traits were selected. C. tepejilote is an arboreal palm with a single stem up to $5 \mathrm{~m}$ tall. It is common in the understory of Los Tuxtlas Reserve, forming dense patches in places where slight disturbances have occurred (Oyama, 1990). The small, greenish-yellow, wind-pollinated flowers appear from October to December (Otero-Arnaiz and Oyama, 2001). Seeds are mainly gravity-dispersed, although several species of birds and bats eat the fruits (Trejo-Pérez, 1989), and seed predation by rodents is common (Oyama, 1991, 1997). Demographic data from permanent plots followed for 4 years (Oyama, 1990) showed that the seed and seedling stages have the highest mortality rates. First reproduction was recorded in palms higher than $50 \mathrm{~cm}$. Most mature individuals produce flowers or fruits during consecutive years, and about $12 \%$ of pistillate flowers produced fruits.

The second species, C. elatior, is the only truly vine like and climbing member of the genus, and hence is one of the most distinctive species (Hodel, 1992; Henderson et al, 1995), with a single stem that reaches up to $22 \mathrm{~m}$ in length and up to $2 \mathrm{~cm}$ in diameter. C. elatior is uncommon (Hodel, 1992). In Mexican rainforest, it may be found in shady sites and occasionally on the slopes of hills. Flowering takes place between February and June (Aguilar, 1986), when small greenish-yellow flowers are produced. Petals of male flowers are joined at the tips and at the top of the pistillode. These flowers are fragrant and have sticky pollen, which can be accessed through lateral slits between the petals (Hodel, 1992; Henderson et al, 1995). Accordingly, insect pollination has been suggested (Henderson, 1986). In one population of Los Tuxtlas, pooled demographic data of C. elatior collected over 4 years (Luna, 1999) showed that mortality was high at adult stages. Reproductive structures were produced by only 83 individuals out of 308 palms scored. Most of these reproduced only once during this period.

\section{Study population and field methods}

The study was conducted in a 640-ha lowland tropical rain forest at Los Tuxtlas Field Station, in southeast Mexico (long. $95^{\circ} 04^{\prime}-95^{\circ} 09^{\prime} \mathrm{W}$, lat. $18^{\circ} 34^{\prime}-18^{\circ} 36^{\prime} \mathrm{N}$, alt. $150-700 \mathrm{~m}$ a.s.1.). Annual rainfall is approximately $4700 \mathrm{~mm}$, and annual mean temperature is $23^{\circ} \mathrm{C}$. Full descriptions of the region have been detailed in González et al (1997).

For C. tepejilote, 188 palms were mapped in a lattice of 24 quadrats of $25 \mathrm{~m}^{2}$ each in a mature forest plot of $600 \mathrm{~m}^{2}$. This species had an aggregated spatial pattern and a density of 1097 individuals $>0.5 \mathrm{~m}$ in a vegetation census of 1 ha (Bongers et al, 1988). C. elatior was found along a steep slope of 'El Vigia' mountain in Los Tuxtlas Reserve. A total of 309 palms were mapped in an area of $550 \mathrm{~m}$ long $\times 200 \mathrm{~m}$ wide: a population density of 28 individuals/ha, excluding seedlings. These palms showed a nonuniform spatial distribution, consisting of three main areas within the sampled population.

In both species, three pinnae from the youngest leaf were collected from each palm, excluding seedlings to minimize a demographic impact. Samples were frozen in liquid nitrogen and stored at $-70^{\circ} \mathrm{C}$ until processed for enzyme analysis.

\section{Laboratory and analytical methods}

Leaf samples of 126 individuals of C. tepejilote and 183 of C. elatior palms were cut finely and ground in an extraction buffer that was prepared with three parts YO buffer (Yeh and O'Malley, 1980) and one part Veg II buffer (Cheliak and Pitel, 1984). Enzyme genotypes were obtained using standard methods for starch gel electrophoresis (Soltis and Soltis, 1989; Kephart, 1990). In all, 31 polymorphic loci of $C$. tepejilote and 27 of C. elatior were identified from 18 enzymes using four buffer systems: (1) C system, Lithium-borate (pH 8.3) (Stuber et al, 1988) was used to resolve diaphorase 'Dia' (Cheliak and Pitel, 1984), glucose 6-phosphate dehydrogenase 'G6pd' (Soltis et al, 1983), glutamate dehydrogenase 'Gdh' (Conkle et al, 1982), esterase 'Est' (Selander et al, 1986), leucine aminopeptidase 'Lap' (Werth, 1985), glutamate oxaloacetate transaminase 'Got' (Wyatt, 1989), cathodic 'Cpx' and anodic 'Apx' peroxidase (Hakim-Elahi, 1981), and rubisco 'Rub' (E.C. 4.1.1.39). (2) D system, histidinecitrate ( $\mathrm{pH}$ 6.5) (Stuber et al, 1988) resolved malate dehydrogenase 'Mdh' (Conkle et al, 1982), phosphoglucomutase 'Pgm' (Soltis et al, 1983), malic enzyme 'Me' (Soltis et al, 1983) and phosphoglucose isomerase 'Pgi' (Conkle et al, 1982). (3) Morpholine-citrate pH 6.1 (Wendel and Weeden, 1989) resolved acid phosphatase 'Acph' (Hakim-Elahi, 1981), 6-phosphogluconate dehydrogenase '6pgd' (Cheliak and Pitel, 1984), isocitrate dehydrogenase 'Idh' (Soltis et al, 1983) and shikimate dehydrogenase 'Sdh' (Werth, 1985). (4) PP system, a discontinuous sodium-borate/tris-citrate system $(\mathrm{pH}$ 7.5) (Mitton et al, 1979) was only used to resolve menadione reductase 'Mnr' (Conkle et al, 1982). Allozymes had banding patterns consistent with expected quaternary structures (Wendel and Weeden, 1989; Soltis and Soltis, 1989). The mode of inheritance for the isozyme patterns was not further tested by crossing. Putative loci and alleles were designated sequentially. The one with the most anodally migrating isozyme or alleles was designated as ' 1 ', the next as ' 2 ' and so on.

Spatial structure analyses were conducted separately for each allele at each polymorphic locus in both species, using Moran's I spatial autocorrelation statistics (Sokal and Oden, 1978). Alleles with three or fewer copies in the sample were excluded as noninformative for the spatial analysis. For diallelic loci, the autocorrelation coefficients 
for each allele are identical, and thus only one value was considered. At multialleleic loci, the values of the most common allele at each locus were excluded when the $I$-averages were calculated. This procedure results in statistical near-independence among the remaining values (Epperson, 2003), and allows the standard errors of average $I$-statistics to be estimated accurately. Average $I$-values use the same information as most estimates of spatial covariance or conditional kinship, $R$, and indeed if the fixation index is known and certain conditions obtain, the results for $I$ can be extended to $R$ estimates, which had previously unknown distributions (Epperson, 2003).

In the calculation of allele-specific I-statistics, each pair of individuals was assigned to one distance class according to the Euclidean distance separating the two palms. As small-scale measures represent the spatial structure more accurately, the upper limit of the first distance class was designed based on an estimate of the average distance that separates the nearest neighboring individuals. Thus, the majority of the neighboring pairs were included in this class. The average number of comparisons over loci for each distance class is shown in Tables 1 and 2. The distance classes constructed for $C$. tepejilote were: (1) $0<2.5$, (2) $2.5<5$, (3) $5<7.5$, (4) $7.5<10$, (5) $10<15$, (6) $15<20$, (7) $20<25$ and (8) $25-32 \mathrm{~m}$. Those for C. elatior were: (1) $0<10$, (2) $10<25$, (3) $25<50$, (4) $50<100$, (5) $100<200$, (6) $200<300$ and (7) $300<600 \mathrm{~m}$.

Unweighted Moran's I-statistics $\left(I_{\mathrm{u}}\right)$ were calculated for each allele and distance class (Sokal and Oden, 1978). Each $I_{\mathrm{u}}$-value was tested for significant deviation from the expected value, $E\left(I_{\mathrm{u}}\right)=-1 /\left(n_{i}-1\right)$ under the null hypothesis of random spatial distribution (Cliff and Ord, 1981). Arithmetic averages of $I_{\mathrm{u}}$ and $E\left(I_{\mathrm{u}}\right)$ were calculated separately across alleles for all loci, for each sample. In addition, the variance of each average $I_{\mathrm{u}}$ value was estimated by $\sigma^{2} I_{\mathrm{u}}=\left(\sum \operatorname{var}\left(I_{\mathrm{u}}\right)_{i}\right)\left(k^{2}\right)^{-1}$ (Epperson, 2003). Furthermore, significance tests for the average values of each distance class were developed by estimating the standard errors of $\bar{I}_{\mathrm{u}}$ under the null hypothesis as $\operatorname{SE}\left(I_{\mathrm{u}}\right)=\left(\sigma^{2} I_{\mathrm{u}}\right)^{1 / 2}$. These values were used directly to build $95 \%$ confidence intervals for the average values, because the theoretical results further allow the assumption that the standard errors on the $I$-averages under the null hypothesis are scarcely affected by the spatial structure (Epperson et al, 1999; Epperson, 2003).

Significant positive $I$-values indicate that pairs of individuals in the distance class considered have more alleles in common than would be expected by chance, whereas a significant negative $I$-value indicates that such individuals have fewer alleles in common. Statistical significance of each set of I-statistics for mutually exclusive distance classes, or I correlogram, was tested using Bonferroni's criteria (Sakai and Oden, 1983). All Moran's I spatial analyses were performed using Wartenberg's SAAP computer program (1989). Finally, the null hypothesis that Moran's I did not differ significantly from the expected value, among all individuals in the population, was tested using $\mathrm{SND}_{\mathrm{u}}=\left(\left(I_{\mathrm{u}}-E\left(I_{\mathrm{u}}\right)\right) \mathrm{SE}\left(I_{\mathrm{u}}\right)^{-1}\right)$, under the assumption that samples are drawn at random from a normal distribution (Sokal and Oden, 1978). Values of the SND $\geq 1.96$ or $\leq-1.96$ indicate that $I$-value differs significantly from the null expectation with a two-tailed probability of 0.05 .

In addition, weighted average Moran's I-statistics were estimated to obtain a more accurate measure of the Iaverage over alleles for all loci, because the inspection of the estimated standard errors of $I$-values indicated dissimilar stochastic and statistical variances among alleles as a result of differences in final sample size among loci. It has been noted that to calculate weighted $I$-statistics requires a priori information on the weights (Epperson, 2003). Accordingly, standard errors of $I-$ values were used to calculate weighted averages of Moran's I-statistics $\left(I_{\mathrm{w}}\right)$ for each distance class and to provide more appropriate consensus correlograms, using the formula:

$$
I_{\mathrm{w}}=\sum_{i j} w_{i}\left(I_{\mathrm{u}}\right)_{i}\left(\sum_{i} w_{i}\right)^{-1}
$$

where $w_{i}$ is the inverse of the standard error of $I_{\mathrm{u}}$-value for $i$ th allele, so $w_{i}=1 / \operatorname{SE}\left(\left(I_{\mathrm{u}}\right)_{i}\right) ;$ and $\left(I_{\mathrm{u}}\right)_{i}$ is the

Table 1 Summary of Moran's I spatial autocorrelation coefficients of 59 alleles in one population of C. tepejilote for eight distance classes

\begin{tabular}{|c|c|c|c|c|c|c|c|c|}
\hline \multirow[t]{2}{*}{ Parameter } & \multicolumn{8}{|c|}{ Distance class (upper bound, $m$ ) } \\
\hline & $1(2.5)$ & $2(5.0)$ & $3(7.5)$ & $4(10)$ & $5(15)$ & $6(20)$ & $7(25)$ & $8(32)$ \\
\hline Average of joins & 177 & 405 & 539 & 600 & 1263 & 929 & 483 & 184 \\
\hline \multicolumn{9}{|l|}{ Unweighted } \\
\hline Average & 0.0085 & -0.0098 & -0.0051 & -0.0076 & -0.0105 & -0.0132 & -0.0180 & -0.0393 \\
\hline Variance & 0.00009 & 0.00004 & 0.00003 & 0.00002 & 0.00001 & 0.00001 & 0.00003 & 0.00008 \\
\hline Standard error & 0.00965 & 0.00625 & 0.00535 & 0.00490 & 0.00310 & 0.00376 & 0.00527 & 0.00876 \\
\hline SND & 1.9970 & 0.1546 & 1.0678 & 0.6468 & 0.0930 & -0.6442 & -1.3599 & -3.2567 \\
\hline$P$-value (two tails) & 0.04583 & 0.87682 & 0.28552 & 0.51763 & 0.92590 & 0.51958 & 0.17383 & 0.00113 \\
\hline Average $E(I)$ & -0.0108 & -0.0108 & -0.0108 & -0.0108 & -0.0108 & -0.0108 & -0.0108 & -0.0108 \\
\hline Average - Average $E(I)$ & 0.0193 & 0.0010 & 0.0057 & 0.0032 & 0.0003 & -0.0024 & -0.0072 & -0.0285 \\
\hline \multicolumn{9}{|l|}{ Weighted } \\
\hline Average & 0.0093 & -0.0087 & -0.0032 & -0.0071 & -0.0109 & -0.0134 & -0.0182 & -0.0361 \\
\hline Variance & 0.00008 & 0.00003 & 0.00002 & 0.00002 & 0.00001 & 0.00001 & 0.00002 & 0.00007 \\
\hline Standard error & 0.00888 & 0.00570 & 0.00483 & 0.00451 & 0.00285 & 0.00348 & 0.00492 & 0.00810 \\
\hline SND & 2.2012 & 0.2780 & 1.4482 & 0.7077 & -0.2145 & -0.8850 & -1.5967 & -3.1833 \\
\hline$P$-value (two tails) & 0.02772 & 0.78101 & 0.14756 & 0.47913 & 0.83016 & 0.37616 & 0.11033 & 0.00146 \\
\hline Average $E(I)$ & -0.01028 & -0.01025 & -0.01023 & -0.01028 & -0.01028 & -0.01030 & -0.01034 & -0.01032 \\
\hline Average - Average $E(I)$ & 0.01955 & 0.00158 & 0.00700 & 0.00319 & -0.00061 & -0.00308 & -0.00786 & -0.02577 \\
\hline
\end{tabular}


Table 2 Summary of Moran's I spatial autocorrelation coefficients of 53 alleles in one population of C. elatior for seven distance classes

\begin{tabular}{|c|c|c|c|c|c|c|c|}
\hline \multirow[t]{2}{*}{ Parameter } & \multicolumn{7}{|c|}{ Distance class (upper bound, m) } \\
\hline & $1(10)$ & $2(25)$ & $3(50)$ & $4(100)$ & $5(200)$ & $6(300)$ & $7(600)$ \\
\hline Average of joins & 287 & 584 & 692 & 992 & 3003 & 1769 & 1284 \\
\hline \multicolumn{8}{|l|}{ Unweighted } \\
\hline Average & 0.0387 & -0.0017 & 0.0036 & -0.0008 & -0.0160 & -0.0106 & -0.0143 \\
\hline Variance & 0.00009 & 0.00005 & 0.00004 & 0.00003 & 0.00001 & 0.00001 & 0.00002 \\
\hline Standard error & 0.00938 & 0.00691 & 0.00617 & 0.00506 & 0.00227 & 0.00354 & 0.00404 \\
\hline SND & 5.1078 & 1.0925 & 2.0786 & 1.6791 & -2.9955 & -0.3736 & -1.2619 \\
\hline$P$-value (two tails) & $<0.00001$ & 0.27439 & 0.03762 & 0.09315 & 0.00274 & 0.70840 & 0.20695 \\
\hline Average $E(I)$ & -0.0092 & -0.0092 & -0.0092 & -0.0092 & -0.0092 & -0.0092 & -0.0092 \\
\hline Average - Average $E(I)$ & 0.0479 & 0.0075 & 0.0128 & 0.0085 & -0.0068 & -0.0013 & -0.0051 \\
\hline \multicolumn{8}{|l|}{ Weighted } \\
\hline Average & 0.0335 & -0.0062 & -0.0028 & -0.0014 & -0.0133 & -0.0096 & -0.0117 \\
\hline Variance & 0.000057 & 0.000026 & 0.000023 & 0.000015 & 0.000003 & 0.000008 & 0.000009 \\
\hline Standard error & 0.00758 & 0.00506 & 0.00476 & 0.00386 & 0.00182 & 0.00276 & 0.00301 \\
\hline SND & 5.4831 & 0.3500 & 1.0772 & 1.6730 & -2.8959 & -0.6088 & -1.2461 \\
\hline$P$-value (two tails) & $<0.00001$ & 0.72634 & 0.28139 & 0.09433 & 0.00378 & 0.54266 & 0.21273 \\
\hline Average $E(I)$ & -0.00801 & -0.00796 & -0.00791 & -0.00789 & -0.00806 & -0.00796 & -0.00790 \\
\hline Average -Average $E(I)$ & 0.04155 & 0.00177 & 0.00513 & 0.00645 & -0.00527 & -0.00168 & -0.00375 \\
\hline
\end{tabular}

unweighted Moran's I-coefficient for ith allele. Thus, the variance of $I_{\mathrm{w}}$ was estimated by means of $\sigma^{2} I_{\mathrm{w}}=\left(\sum w_{i}^{2}\right)$ $\left(\operatorname{var}\left(\left(I_{\mathrm{u}}\right)_{i}\right)\right)\left(\left(\sum w_{i}\right)^{2}\right)^{-1}$. Hence $\operatorname{SE}\left(I_{\mathrm{w}}\right)=\left(\sigma^{2} I_{\mathrm{w}}\right)^{1 / 2}$, which was used directly to construct $95 \%$ confidence intervals for the average values. The weighted average expected value, under the null hypothesis of a random spatial distribution, was estimated for each distance class as $E\left(I_{\mathrm{w}}\right)=\left(\sum w_{i}\left(E\left(I_{\mathrm{u}}\right)_{j}\right)\right)\left(\sum w_{i}\right)^{-1}$. As before, a standard normal deviate $\mathrm{SND}_{\mathrm{w}}$ was developed for the testing of significance within distance classes.

A statistical test was created to evaluate whether or not there was a difference between $C$. elatior and $C$. tepejilote in the amount of spatial autocorrelation in the shortest distance classes, which in both species contained primarily nearest neighbors. The test was formed by subtracting the excess of average Moran's I for C. tepejilote, $I_{\mathrm{t}}$ over its expected value under the null hypothesis of random distribution $E\left(I_{t}\right)$, from the equivalent excess for $C$. elatior. This difference, denoted $Y$, was explicitly calculated as $Y=$ $\left(\left(I_{\mathrm{e}}-E\left(I_{\mathrm{e}}\right)\right)-\left(I_{\mathrm{t}}-E\left(I_{\mathrm{t}}\right)\right)\right)$. The value of $Y$ is then approximately distributed as normal with mean zero and variance $\sigma_{Y}^{2}=\operatorname{SE}\left(I_{\mathrm{e}}\right)^{2}+\mathrm{SE}\left(I_{\mathrm{t}}\right)^{2}$, under the null hypothesis that the averages are the same. The standard error of the difference $Y$ would then be $\operatorname{SE}(Y)=\left(\sigma_{Y}^{2}\right)^{1 / 2}$. Consequently the coefficent $Y / \operatorname{SE}(Y)$ was tested for statistical significance using a one-tailed probability of 0.05 . Thus, the excess of average $I_{\mathrm{e}}$ over $E\left(I_{\mathrm{e}}\right)$ is regarded as statistically different from the excess of average $I_{t}$ over $E\left(I_{t}\right)$ at the $P<0.05$ significance level if $Y$ is greater than 1.645. In addition, the standard error of $Y$ was used directly to construct $90 \%$ confidence intervals using \pm 1.645 times the $\operatorname{SE}(Y)$. Y-statistics were calculated separately for unweighted and weighted I-averages.

Neighborhood sizes for C. elatior and C. tepejilote were estimated by using the averaged (over alleles and loci) observed values minus the averaged expected values of Moran's I-statistics for the first distance class, and comparing these to theoretical values in Table 4 of Epperson et al (1999).

\section{Results}

A total of 776 Moran's I spatial autocorrelation coefficients for 97 alleles of $C$. tepejilote and 637 I-coefficients for 91 alleles of C. elatior were calculated including alleles with less than four copies (seven and 11 alleles for each species, respectively). After the most common allele of each locus was excluded, 59 alleles of 31 polymorphic loci of C. tepejilote and 53 alleles of 27 polymorphic loci of $C$. elatior were used to estimate the unweighted and weighted values of the $I$-average (Tables 1 and 2).

The spatial structure of the C. tepejilote population was examined using a total of 472 Moran's I spatial autocorrelation coefficients from the eight distance classes. Among these, 74 (15.7\%) I-values were significantly different (27 at $P<0.01$, and 47 at $P<0.05$ ) from the expected value, under the null hypothesis of random distribution. For each distance class, the overall percentages of significant I-statistics, and the total of positive $(+)$ and negative $(-)$ significant values were: $(1) 15.25$ $(+7,-2) ;(2) 13.56(+5,-3)$; (3) $16.95(+7,-3)$; (4) 22.03 $(+7,-6)$; (5) $22.03(+6,-7)$; (6) $13.56(+2,-6)$; (7) 10.17 $(+0,-6)$ and (8) $11.86(+0,-7)$. For example, for the particularly important first distance class, nine out of 59 $(15.25 \%)$ values were statistically significant; seven of these were positive and two were negative. Correlograms, entire sets of $I$-statistics, for eight distance classes showed significant values at the 5\% level for $15(25.42 \%)$ out of a total of 59 cases.

For C. elatior, the spatial pattern of genetic structure was examined using a total of 371 Moran's I spatial autocorrelation coefficients for the seven distance classes. In this case, $46(12.4 \%)$ I-values were significantly different (26 at $P<0.01$, and 20 at $P<0.05$ ) from the expected value, $E\left(I_{\mathrm{u}}\right)=-0.00925$, for randomly distributed alleles. For each distance class, the overall percentages of significant I-statistics, and the total positive $(+)$ and negative (-) significant values were: (1) 16.98 $(+9,-0)$; (2) $13.21(+5,-2)$; (3) $7.55(+2,-2)$; (4) 11.32 $(+5,-1) ;(5) 13.21(+1,-6) ;(6) 15.09(+5,-3)$ and $(7)$ $9.43(+0,-5)$. For example, for the particularly 


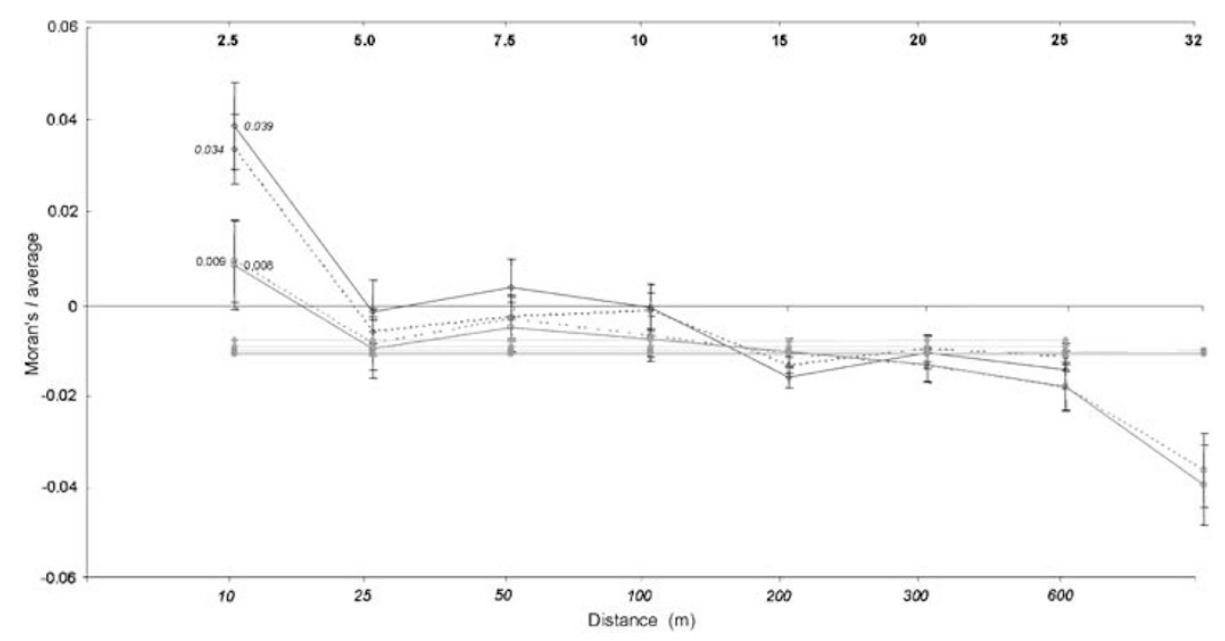

Figure 1 Spatial autocorrelation consensus correlograms (Moran's $I$ ) for $C$. tepejilote $(\bigcirc, \bullet)$ and C. elatior $(\diamond, \diamond)$. The solid symbols indicate the average expected values under the null hypothesis of a random distribution. The dotted lines represent weighted average values and the solid lines represent the unweighted average values. The upper bounds on the distance classes are shown in bold types for C. tepejilote and in italics for C. elatior. Standard errors are also shown.

important first distance class $(0$ to $<10 \mathrm{~m})$, nine significantly positive cases were observed, whereas no significantly negative cases were detected. Correlograms were statistically significant at the $5 \%$ level in $14(26.42 \%)$ out of a total of 53 cases.

The average values for Moran's I over the 59 alleles of C. tepejilote and the 53 alleles of C. elatior at all allozyme loci for each distance class are listed in Tables 1 and 2. Also, the estimated standard errors under the null hypothesis, the corresponding standard normal deviate $Z$ and the $P$-values for two-tailed tests are shown. Overall, the average correlogram for the $C$. elatior population indicates short distance autocorrelations, whereas that for $C$. tepejilote shows a nearly random distribution of genotypes over the sampled area (Figure 1). For the C. tepejilote population, the unweighted and weighted Moran's I-averages for the first distance class were equal to 0.0085 and 0.0093 , respectively, which were statistically significant for a two-tailed test $(P=0.046$ and 0.028 , respectively). Moreover, there was a significant negative average autocorrelation at the largest distance class (eight). For the C. elatior population, consensus correlograms indicate that the highest relative levels of genetic similarity occur among individuals separated by $<10 \mathrm{~m}$, and unweighted and weighted average values for the first distance class were 0.0387 and 0.0335 , respectively (two-tailed test, $P<0.00001$ in both estimations).

The statistical significance test of the null hypothesis, that the amount of autocorrelation for the shortest distance classes (which for each species contains primarily nearest neighbors) is the same for $C$. elatior and $C$. tepejilote, was rejected at a one-tailed probability of 0.05 ( $90 \%$ of the distribution), when it was evaluated using either unweighted or weighted I-averages. The amount of spatial genetic structure of the $C$. elatior population was shown to be significantly greater than that of the $C$. tepejilote population, with unweighted $(\mathrm{SND}=2.129$, $P=0.0166)$ and weighted $(\mathrm{SND}=1.885, P=0.0297)$ summary statistics. In addition, unweighted Moran's Iaverages estimated for the $C$. elatior population and the C. tepejilote population were statistically different at a
$95 \%$ confidence two-tailed test $(\mathrm{SND}=2.129, P=0.0333)$, although the overlap of those distributions was not rejected when weighted autocorrelation averages were tested at the same significance level.

Neighborhood size was approximately 100 individuals in the case of $C$. elatior and about 300 for C. tepejilote.

\section{Discussion}

Nonrandom spatial genetic patterns within natural populations of $C$. tepejilote and of $C$. elatior, and differences in the extent of genetic isolation by distance between them, were precisely measured in this study. Spatial genetic structure was significantly higher in $C$. elatior than in C. tepejilote. For the latter population, Moran's I spatial autocorrelation values were less than 0.01 , yet were statistically distinguishable from a random distribution. For the population of $C$. elatior, mean autocorrelation values for the shortest distances were comparable to I-values of 0.075 for Psychotria nervosa (Dewey and Heywood, 1988), 0.05 for Quercus laevis (Berg and Hamrick, 1995) and 0.05 for an old growth population of Pinus strobus (Epperson and Chung, 2001). Weak spatial structure at the $C$. elatior $\left(I_{\mathrm{u}}=0.034\right.$, $\left.I_{\mathrm{w}}=0.039\right)$ and C. tepejilote $\left(I_{\mathrm{u}}=0.008, I_{\mathrm{w}}=0.009\right)$ populations is in broad terms consistent with those of some predominantly outcrossing, woody perennial plant species reported previously.

Precise estimates of effective population size are critical for interpreting many microevolutionary processes in population biology. The degree of spatial genetic structure at quasi-stationarity stage under an isolation-by-distance process is primarily a function of Wright's neighborhood size (Sokal and Wartenberg, 1983). Neighborhood size can be influenced by overlapping generations, spatial-temporal variations in number of reproductive individuals, variance in reproductive success and biased sex ratios (Álvarez-Buylla et al, 1996). The dioecious species C. tepejilote and $C$. elatior did not show significant departures from the theoretically expected sexual proportions (Oyama, 1990; Luna, 1999). In such cases, the value of neighborhood 
size represents the total number of males and females. For C. tepejilote, 1097 individuals with stem $>0.5 \mathrm{~m}$ were recorded within $1 \mathrm{ha}$, where this species exhibited an aggregated spatial pattern (Bongers et al, 1988). Stable structure both of size and life stages indicated that reproductive plants constituted about one-third (109 out of 341) of the sample (Oyama, 1990). Then, assuming that the sex ratio of $C$. tepejilote remains equal to $1: 1$, the estimated neighborhood size of 300 individuals ( $\sim 150$ males plus $\sim 150$ females) would occupy an approximate area of 1 ha. For $C$. elatior, the estimated neighborhood size of 100 reproductive individuals ( $\sim 50$ males plus $\sim 50$ females) would be contained in 13.2 ha (1.2-fold the total sampled area), assuming similar patterns of plant distribution and reproduction than in the study site.

Spatial patterns of genetic variation within populations depend primarily on the patterns and distance of pollen and seed dispersal. Contrasting pollination mechanisms influence pollen movement distances, which, together with spatial distribution of the flowering palms and the individual reproductive periodicity, are the primary determinants of mating by proximity in these populations. For $C$. tepejilote, wind mediates pollination between reproductive palms distributed at random among the dense understory vegetation at the sampled site (Oyama, 1990). Its copious pollen release is triggered by strong winds during the local tropical storm season. Unpredictable fluctuations of pollen movement may enhance the genetic variation of this wind-pollinated species by elevating the mating-pair heterogeneity. In this population, $32 \%$ of the total palms reproduced during the 4 years study period, most of them $(60 \%)$ having three or four annual flowering events. Paternity analysis suggested that almost one-third of seedlings had sires located outside the sampled area (Otero-Arnaiz and Oyama, unpublished data). This level of pollen flow is consistent with that in other wind-pollinated species (Muona, 1990; Schnabel et al, 1991). For C. elatior, mating between spatially nonuniform reproductive palms through pollinators such as thrips occurs in the subcanopy. Reproductive individuals constituted $27 \%$ of the total palms, and $68 \%$ of those flowered once or twice during the 4-year study period. Thus, limited pollen flow may restrict genetic recombination by decreasing the number of mating partners. Seeds in the same inflorescence could, as a result, be more genetically related than half-sibs. The population of C. elatior has high levels of isozyme genetic variation, although less than $C$. tepejilote (Luna, 1999; Luna and Oyama, unpublished data). Accordingly, mating patterns may influence the differences of genetic similarity among the nearest neighbors between the studied palms.

Fruit dispersal in both species is predominantly by gravity. However, secondary dispersal could occasionally cause seed movements distant from the maternal palms, which was evident in offspring recruitment observed during some periods at sites without local fruit production. In the $C$. elatior site, all fruits in 1 year were produced from just one female palm. The following year, there were many new juvenile plants established in the study site. Since mature seeds germinate in approximately 9 months (M Sinaca-Colín, personal communication), and the seedling-seed rate has been estimated at $3 \%$, it is plausible to think that this recruitment is coming from seed dispersal of palms located in the vicinity of the population studied. Gravity-dispersed seeds from maternal palms in the surrounding area cannot explain such recruitment, given that the study site is flanked by downslopes and is located on one of the highest mountains at the Los Tuxtlas Reserve. Accordingly, the offspring have likely arisen from animal-dispersed seeds from outside of the sampled area. In the case of $C$. tepejilote, understory vegetation between two permanent plots was cut down 50 years ago, but undisturbed during the last 15 years. In 2002 , most of the palms $(\sim 90 \%)$ sampled in this area were seedlings and juveniles $<0.5 \mathrm{~m}$ in height. There were six (out of 212) plants with fruits. This regenerative local population may be attributable to extensive seedmediated gene flow. Independent and long-distance dispersal of single-seeded fruits may account for extensive gene flow and little spatial genetic structuring, in contrast to the effects of correlated seed dispersal, for example, in intact multiseeded fruits (Epperson and Alvarez-Buylla, 1997; Chung et al, 2000; Chung et al, 2003b).

Factors that regulate population dynamics also influence spatial distribution of individuals, and thus the small amount of spatial genetic structuring detected within the study populations. The initial genetic correlation established in the gravity-dispersed progeny may decrease due to thinning processes and overlapping of survivors from different age cohorts. Seeds of $C$. elatior and of $C$. tepejilote had high mortality rates. Seedlings were produced by 2.6 and $7.2 \%$ of seeds, respectively. For C. tepejilote, about one-third of the viable seeds that reached the soil were ingested by a heteromyid rodent, Heteromys desmarestianus (Oyama, 1997). In both species, only a small proportion of seedlings survive to replace adults. Thus, the genetic correlations among young individuals may have diminished as they matured and were thinned out (Hamrick et al, 1993; Epperson and Álvarez-Buylla, 1997; Chung et al, 2003a).

The density of reproductive individuals is influenced by resource allocation to growth, survivorship and reproduction within populations (Stearns, 1992). Strong differences in these factors were noted between the study species. C. elatior showed high adult mortality, infrequent individual reproduction and peak fruiting years. In contrast, $C$. tepejilote showed much higher adult survivorship, annual individual reproduction and more regular fruit production. These differences may have resulted in differential densities, and hence weaker spatial genetic structure in the site of the common, wind-pollinated and understory species. For long-lived species, especially polycarpic plants, overlapping generations and seed shadows may greatly mask the genetic relatedness among individuals of the same age (Chung et al, 2003a; Walter and Epperson, 2004). The lower spatial genetic structure of $C$. tepejilote could thus be the result of a more diverse mixture of family patches, each containing a larger number of individuals, longer generations and higher genetic variation within populations, as compared to C. elatior. Finally, it is apparent that a better understanding of the dynamics of spatial genetic structure within populations will require explicit research into the processes that regulate the degree and time scale both of transient and long-term spatial genetic structure. 


\section{Acknowledgements}

Thanks go to M Martínez-Ramos, F Sánchez-Garduño and Mark Olson for providing insightful comments on this project. Skillful suggestions from Eric R Myers and two anonymous reviewers improved the content of this paper. VM Zarco-Espinosa, S Sinaca-Colín, M SinacaColín and P Cuevas-Reyes provided expert field assistance. H Ferreira edited the figure. This research was supported by UNAM and CONABIO (B024) projects to $\mathrm{KO}$, and by grants from CONACyT and DGEP-UNAM to RL.

\section{References}

Aguilar AR (1986). El Género Chamaedorea Willd (Palmae) en el Estado de Veracruz. BSc Thesis, Universidad Veracruzana, Mexico.

Álvarez-Buylla ER, García-Barrios R, Lara-Moreno C, MartínezRamos M (1996). Demographic and genetic models in conservation biology: applications and perspectives for tropical rain forest tree species. Annu Rev Ecol Syst 27: 387-421.

Barbujani G (1987). Autocorrelation of gene frequencies under isolation by distance. Genetics 117: 777-782.

Berg EE, Hamrick JL (1995). Fine-scale genetic structure of a turkey oak forest. Evolution 49: 110-120.

Bongers F, Pompa J, Meave J, Carabias J (1988). Structure and floristic composition of the lowland rain forest of Los Tuxtlas, México. Vegetatio 74: 55-80.

Cheliak WM, Pitel JA (1984). Techniques for starch gel electrophoresis of enzymes from forest tree species. Information Report PI-X42. Petawawa National Forestry Institute, Chalk River, Ontario.

Chung MG, Chung MY, Oh GS, Epperson BK (2000). Spatial genetic structure in a Neolitsia sericea population (Lauraceae). Heredity 85: 490-497.

Chung MY, Epperson BK, Chung MG (2003a). Genetic structure of age classes in Camellia japonica (Theaceae). Evolution 57: 62-73.

Chung MY, Nason JD, Epperson BK, Chung MG (2003b). Temporal aspects of the fine-scale genetic structure in a population of Cinnamomum insularimontanum (Lauraceae). Heredity 90: 98-106.

Cliff AD, Ord JK (1981). Spatial Processes: Models and Applications. Pion Ltd: London.

Conkle MT, Hodgskiss PD, Nunnally LB, Hunter SC (1982). Starch gel electrophoresis of conifer seeds: a laboratory manual. General Technical Report PSW-64. USDA. Forest Service. Pacific Southwest Forest and Range Experiment Station, Berkeley, CA.

Dewey SE, Heywood JH (1988). Spatial genetic structure in a population of Psychotria nervosa, I. Distribution of genotypes. Evolution 42: 834-838.

Epperson BK (2003). Geographical Genetics. Princeton University Press: Englewood Cliffs, NJ.

Epperson BK, Álvarez-Buylla ER (1997). Limited seed dispersal and genetic structure in life stages of Cecropia obtusifolia. Evolution 51: 275-282.

Epperson BK, Chung MG (2001). Spatial genetic structure of allozyme polymorphisms within populations of Pinus strobus (Pinaceae). Am J Bot 88: 1006-1010.

Epperson BK, Huang Z, Li TQ (1999). Measures of spatial structure in samples of genotypes for multiallelic loci. Genet Res 73: 251-261.

Gentry AH (1991). The distribution and evolution of climbing plants. In: Putz F, Mooney HA (eds) The Biology of Vines. Cambridge University Press: Cambridge, MA. pp 3-49.
González E, Vogt R, Dirzo R (1997). La Historia Natural de Los Tuxtlas. UNAM: Mexico.

Hakim-Elahi A (1981). Temporal Changes in the Population Structure of the Slender Wildoat (Avena barbata) as Measured by Allozyme Polymorphism. PhD Thesis, University of California, Davis.

Hamilton M (1999). Tropical tree gene flow and seed dispersal. Nature 401: 129-130.

Hamrick JL, Murawski DA, Nason JD (1993). The influence of seed dispersal mechanisms on the genetic structure of tropical tree populations. Vegetatio 107/108: 281-297.

Henderson A (1986). A review of pollination studies in the Palmae. Bot Rev 52: 221-259.

Henderson A, Galeano G, Bernal R (1995). Field Guide to the Palms of the Americas. Princeton University Press: Englewood Cliffs, NJ.

Hodel DR (1992). Chamaedorea Palms: The Species and Their Cultivation. Allen Press: Kansas.

Kephart S (1990). Starch gel electrophoresis of plant isozymes: a comparative analysis of techniques. Am J Bot 77: 693-712.

Luna R (1999). Demografía y Genética Poblacional de Chamaedorea elatior en la Selva de Los Tuxtlas, Veracruz. BSc Thesis, UNAM, Mexico.

Malécot $G$ (1948). Les Mathématiques de l'Héredité. Masson: Paris.

Mitton JB, Linhart YB, Sturgeon KB, Hamrick JL (1979). Allozyme polymorphism detected in mature tissue of ponderosa pine. J Hered 70: 86-89.

Muona O (1990). Population genetics in forest tree improvement. In: Brown AHD, Clegg MT, Kahler AL, Weir BS (eds) Plant Population Genetics, Breeding, and Genetic Resources. Sinauer: Massachusetts. pp 282-298.

Otero-Arnaiz A, Oyama K (2001). Reproductive phenology, seed-set and pollination in Chamaedorea alternans H.A. Wendl. An understorey dioecious palm in a rainforest in Mexico. J Trop Ecol 17: 745-754.

Oyama K (1990). Variation in growth and reproduction in the neotropical dioecious palm Chamaedorea tepejilote. J Ecol 78: 648-663.

Oyama K (1991). Seed predation by a curculionid beetle on the dioecious palm Chamaedorea tepejilote. Principes 35: 156-160.

Oyama K (1997). Las plantas. Chamaedorea tepejilote. In: González E, Vogt R, Dirzo R (eds) La Historia Natural de Los Tuxtlas. UNAM: Mexico. pp 107-109.

Sakai AK, Oden NL (1983). Spatial pattern of sex expression in silver maple (Acer saccharum Marsh.) stands. Am Nat 122: 489-508.

Schnabel A, Laushman RH, Hamrick JL (1991). Comparative genetic structure of two co-occurring tree species, Maclura pomifera (Moraceae) and Gleditsia triacanthos (Leguminosae). Heredity 67: 357-364.

Selander RK, Caugant DA, Ochman H, Musser JM, Gilmour MN, Whittam TS (1986). Method multilocus enzyme electrophoresis for bacterial population genetics and systematics. Appl Environ Microbiol 51: 873-884.

Sokal RR, Oden NL (1978). Spatial autocorrelation in biology. 1. Methodology. Biol J Linn Soc 10: 199-228.

Sokal RR, Wartenberg DE (1983). A test of spatial autocorrelation analysis using an isolation-by-distance model. Genetics 105: 219-237.

Soltis DE, Haufler CH, Darrow DC, Gastony CJ (1983). Starch gel electrophoresis of ferns: a compilation of grinding buffers, gel and electrode buffers, and staining schedules. Am Fern J 73: 9-27.

Soltis DE, Soltis PS (1989). Isozymes in Plant Biology. Dioscorides Press: Oregon.

Stearns SC (1992). The Evolution of Life Histories. Oxford University Press: New York.

Stuber CW, Wendel JM, Goodman MM (1988). Techniques and scoring procedures for starch gel electrophoresis of enzymes from 
maize (Zea mays). Technical Bulletin 286. North Caroline State University, North Caroline.

Trejo-Pérez L (1989). Diseminación de semillas por aves en Los Tuxtlas, Veracruz. In: Gómez-Pompa A, del Amo S, VázquezYanes C, Butanda A (eds) Regeneración de Selvas. Continental: México. pp 447-470.

Vekemans X, Hardy OJ (2004). New insights from fine-scale spatial genetic structure analyses in plant populations. Mol Ecol 13: 921-935.

Walter R, Epperson BK (2004). Microsatellite of spatial structure among seedlings in populations of Pinus strobus (Pinaceae). Am J Bot 91: 549-557.

Wartenberg DE (1989). SAAP. A Spatial Autocorrelation Analysis Program. Version 4.3. Exeter Software: Setauket, NY.
Wendel J, Weeden N (1989). Visualization and interpretation of plant isozyme. In: Soltis DE, Soltis PS (eds) Isozymes in Plant Biology. Dioscorides Press: Oregon. pp 5-45.

Werth CR (1985). Implementing an isozyme laboratory at a field station. Va J Sci 36: 53-76.

Wright S (1943). Isolation by distance. Genetics 28: 114-138.

Wyatt R (1989). A General Protocol of Starch Gel Electrophoresis. Manuscript, University Georgia: Athens, Georgia.

Yeh FCH, O' Malley D (1980). Enzyme variations in natural populations of Douglas fir, Pseudotsuga menziesii (Mub.) Franco, from British Columbia. 1. Genetic variation patterns in coastal populations. Silvae Genet 29: 83-92. 